\title{
ESTUDO PSICANALÍTICO DO FILME "DIVÓRCIO: ATÉ QUE O AMOR EXPLODA"
}

\author{
Gisele Meirelles Fonseca-Inacarato \\ Sueli Regina Gallo-Belluzzo \\ Tânia Maria José Aiello-Vaisberg \\ Pontifícia Universidade Católica de Campinas, Campinas-SP, Brasil
}

\begin{abstract}
RESUMO
O presente estudo tem como objetivo refletir sobre a idealização imaginativa do vínculo conjugal que motiva o casamento, mas compromete sua continuidade e o provimento de cuidado aos filhos. O estudo se articulou metodologicamente por meio da abordagem do filme brasileiro "Divórcio: até que o amor exploda", de Pedro Amorim, que permite uma clara apreciação psicanalítica da configuração vincular entre cônjuges, sustentando a produção interpretativa de três campos de sentido afetivo-emocional ou inconscientes relativos ao enredo: "Até que a morte nos separe", "Era vidro e se quebrou" e "Usando os filhos". Deixando claramente demonstrada a imaturidade da idealização, esse estudo aponta para a importância de debate sobre novas formas de associação entre conjugalidade e parentalidade.
\end{abstract}

Palavras-chave: Relações Conjugais; Parentalidade; Cinema; Método Psicanalítico.

\section{PSyChOANALYTIC STUDY OF THE BRAZILIAN FILM "DIVÓRCIO: ATÉ QUE O AMOR EXPLODA"}

\section{Abstract}

The study discussed the imaginative idealization of conjugal bond which motivates marriage but compromises its continuity, as well as the provision of care to the children. The study was methodologically articulated on the approach of the Brazilian movie "Divórcio: até que o amor exploda", directed by Pedro Amorim. The movie allows a clear psychoanalytical appreciation of the connection configuration between spouses, supporting the interpretative production of three affective-emotional meaning fields or unconscious related to the plot: "Until death do us part", "It was glass and it broke" and "Using children". By clearly demonstrating the immaturity of idealization, this study points to the importance of debating on new forms of association between conjugality and parenting.

Keywords: Marital relationships; Parenting; Motion Pictures; Psychoanalytic Method. 


\title{
ESTUDIO PSICOANALÍTICO DE LA PELÍCULA BRASILEÑA "DIVÓRCIO: ATÉ QUE O AMOR EXPLODA"
}

\begin{abstract}
RESUMEN
Este estudio tiene como objetivo reflexionar sobre la idealización imaginativa del vínculo conyugal que motiva el matrimonio, pero compromete su continuidad y la provisión de cuidados a los hijos. Se articuló metodológicamente en el abordaje de la película brasileña "Divórcio: até que o amor exploda", dirigida por Pedro Amorim, que permite una clara apreciación psicoanalítica de la configuración de vinculación entre conyuges, apoyando la producción interpretativa de tres campos del sentido afectivoemocional, o inconscientes relacionados con la trama: "Hasta que la muerte nos separe", "Era vidrio y se rompió" y "Usando los hijos". Dejando claramente demostrada la inmadurez de la idealización, este estudio apunta a la importancia del debate sobre nuevas formas de asociación entre conyugalidad y parentalidad.
\end{abstract}

Palabras clave: Relaciones conyugales; Parentalidad; Cinema; Método psicoanalítico.

Dado o caráter complexo, multifacetado e contraditório da sociedade contemporânea, não nos surpreende constatar que são variados os modelos, nela vigentes, de família, tais como a monoparental, a homoparental, a gerada artificialmente e a recomposta, entre outras (Arrais et al., 2019). Algumas dessas variedades são, possivelmente, novas, enquanto outras, como as que são compostas por casais do mesmo sexo, provavelmente subsistiram, no passado, de modo invisibilizado, por gerarem reprovação social. Além disso, questões diversas, como nível socioeconômico ou ambiente cultural, certamente privilegiam uma ou outra dessas configurações (Leonardo \& Morais, 2017).

Contudo, o grupo conhecido como família nuclear pode ser considerado como uma das mais importantes instituições, entre aquelas que organizam a sociedade atualmente, uma vez que se define, no imaginário social, como o mais satisfatório locus de proteção da criança e do adolescente. Um exemplo bastante claro do valor da família nuclear pode ser encontrado se fizermos um exame minucioso do Estatuto da Criança e do Adolescente, que motiva debates ao redor das condições de aplicabilidade de suas concepções que, em si mesmas, tendem a ser positivamente consideradas.

Sendo correta a afirmação de que coexistem, na atualidade, diversos modelos de família, cabe também lembrar que todos eles, inclusive o da família nuclear, não deixam de sofrer muitas modificações, que se ligam tanto ao acontecer social mais amplo como às mudanças relativas às relações hierárquicas de gênero e aos avanços que permitem medidas de contracepção mais seguras do ponto de vista da saúde. Assim, mesmo essa última versão, constituída pela coabitação domiciliar do casal heterossexual e filhos, vem sofrendo transformações relevantes que se traduzem como novas práticas que se associam a novos valores, normas e padrões de interação, ainda que haja indícios de que casais, que mantêm o vínculo conjugal por longos períodos, tendam a sustentar os papéis de gênero (Alves-Silva et al., 2017).

As alterações que ocorrem, atualmente, na família em geral, e na família nuclear em particular, estão diretamente ligadas à mudança do lugar que as mulheres ocupam em nossa sociedade. Na luta pela igualdade de gênero, os movimentos feministas 
encontraram condições macrossociais propícias à entrada da mulher no mundo laboral que, diminuindo sua dependência financeira do homem, veio favorecer a introdução de alterações na estrutura do casamento, atenuando contornos relativamente às funções dos homens e das mulheres.

Tal movimento tanto ocorreu nas camadas médias e abastadas, levando as mulheres à universidade e à possibilidade de carreira profissional, como nas classes desfavorecidas, pois um grande número de mulheres se sustenta a partir de inserção no mercado de trabalho como mão de obra não qualificada ou exercendo funções de cuidado. Atualmente, tantos as mais pobres, como aquelas que gozam de condição socioeconômica privilegiada, têm conseguido se posicionar de modo mais independente e autônomo em relação ao parceiro, trabalhando, sustentando-se e controlando a natalidade, seja pelo adiamento da maternidade, seja optando por não ter ou diminuir o número de filhos (Bernardi et al., 2019).

Os homens, por sua vez, não deixaram de ser afetados pelo fato de suas companheiras manterem vida profissional fora do lar. Em certos ambientes culturais, o marido passou a participar com maior frequência da execução de tarefas da casa e dos cuidados com os filhos (Souza, 2018), chegando, eventualmente, a se responsabilizar plenamente pela guarda nas famílias patrifocais (Abade \& Romanelli, 2018).

Outros têm resistido mais tenazmente a aderir a uma partilha do cuidado dos filhos e das tarefas domésticas, tanto por iniciativa própria como, em certos casos, em função da atitude das mulheres que têm dificuldade em aceitar a participação do parceiro. De todo o modo, é importante lembrar que a existência de condições objetivas de superação da dependência econômica do homem, tanto nos bairros de classe média, como nas periferias, tem contribuído muito para que, diante de certas situações problemáticas, a separação conjugal seja avaliada, pela mulher, como uma melhor opção para sua vida, numa configuração impensável há poucas décadas.

Portanto, se constatamos, hoje, um aumento no número de separações conjugais (Colégio Notarial, 2021), em nosso país, entendendo que esse fenômeno pode ser creditado, em grande parte, ao fato da mulher ter conquistado independência financeira do marido, o que gera um aumento de famílias matrifocais, torna-se importante lembrar que nos encontraremos, muito frequentemente, diante de mulheres/mães/profissionais que devem dedicar-se com afinco ao trabalho, em função de sua responsabilidade no sustento familiar, mesmo ganhando menos do que o colega de sexo masculino, além de se desdobrar em sua dupla jornada (Bueskens, 2019; Federici, 2019).

Na verdade, sabemos que a divisão sexual do trabalho está, hoje, transformada, uma vez que o marido não sustenta mais a família e assume partes da dupla jornada segundo seu arbítrio pessoal, e que, uma vez ocorrida a separação, torna-se frequente que a mulher venha a arcar sozinha com sustento e cuidado. Essa configuração, que já é frequente, explica certos achados de pesquisa, tais como os obtidos por Batoni (2020) que, pesquisando jovens universitárias, sobre imaginários acerca do futuro, encontrou uma clara desvinculação entre projetos de maternidade e conjugalidade.

Contudo, se temos claro que prevalece o modelo da família nuclear como melhor forma de cuidado dos filhos, enquanto na prática cresce o número de separações, originando, via de regra, um modelo familiar que sobrecarrega ainda mais a mulher, parece-nos importante realizar um exame da vinculação conjugal, pois está bastante claro que há, na atual situação, um descompasso entre conjugalidade e parentalidade, provocado pela obsolescência da tradicional divisão sexual do trabalho. Se o cuidado às novas gerações se encontra institucionalmente a cargo do grupo familiar, mas esse se 
revela, na prática, menos duradouro do que o processo de transição dos filhos para a vida adulta, fica clara a necessidade de repensar tais questões.

Mesmo que, num horizonte mais amplo, não deixemos de considerar que as possibilidades de criação de novas formas de cuidado e proteção à infância são inúmeras (Gottlieb \& DeLoache, 2016), parece-nos relevante pensar a questão a partir daquilo que, hoje, é praticado pela população brasileira. Por esta razão, estabelecemos, como objetivo do presente estudo, refletir sobre a idealização imaginativa do vínculo conjugal, em grupos familiares formados por casal e filhos, a partir da abordagem psicanalítica do filme "Divórcio: até que o amor exploda", de Pedro Amorim (2017).

\section{A PSICOLOGIA PSICANALÍTiCA CONCRETA COMO FUNDAMENTO TEÓRICO- METODOLÓGICO}

Para realizar nosso objetivo de estudar teórico-reflexivamente a questão da idealização do vínculo conjugal, adotaremos a psicologia psicanalítica concreta, que deve ser definida como um referencial teórico-metodológico que se produz a partir da articulação do método psicanalítico de investigação, criado por Freud (1922/1976), com o uso de uma rede de conceitos vinculares, que dispensam a metapsicologia clássica por razões epistemológicas (Bleger, 1963/2007; Politzer, 1928/1998). Esse referencial, que nasceu em Buenos Aires, vem sendo utilizado, em nosso país, em várias pesquisas qualitativas com método psicanalítico (Aiello-Vaisberg et al., 2020; Rosa et al., 2019), inscrevendo-se sob o paradigma estrutural-relacional (Greenberg \& Mitchell, 1994). Entretanto, distingue-se de outras propostas, abarcadas por esse mesmo paradigma, tais como a psicanálise relacional de Mitchell (1988) ou a psicanálise intersubjetiva de Stolorow e Atwood (1992), pelo fato de considerar que os campos vinculares, no âmbito dos quais ocorrem os atos humanos, são sempre afetados pelos contextos macrossociais em que se inserem.

Consistindo na aplicação do método psicanalítico de investigação na busca de interpretação de produção cultural, o presente estudo segue uma configuração de trabalho inaugurada pelo próprio Freud, quando escreveu obras tais como "Delírios e Sonhos na Gradiva de Jensen" (Freud, 1907/1976), "Leonardo da Vinci e uma Lembrança da sua Infância" (1910/1970) e "O Moisés de Michelangelo" (Freud, 1914/1974). Tais iniciativas que devem ser consideradas como relevantes por vários motivos, que incluem o fato de terem revelado fantasias que são socialmente produzidas e compartilhadas.

O filme que aqui utilizamos como apoio para nossas reflexões sobre a idealização do vínculo conjugal - "Divórcio: até que o amor exploda" de Pedro Amorim (2017) - embora apresente em seu título o tema da separação conjugal, aborda diversas fases da relação de um casal, iniciando pela idealização do amor conjugal, seguida pela percepção de que esse tipo de amor é uma ilusão, que é acompanhada por decepções e agressões mútuas. Essa produção cinematográfica, que corresponde à narrativa cômica da história de um relacionamento conjugal, consiste no relato de aventuras e desventuras de um homem e uma mulher que se casam contrariando determinações de um pai profundamente preocupado com a pobreza do noivo, razão mais do que suficiente para desqualificá-lo como pretendente da filha rica.

No conflito entre interesses e sentimentos, prevalece o amor, de modo que os enamorados fogem para casar e viver sua felicidade modestamente. Entretanto, sua

Fonseca-Inacarato, Gallo-Belluzzo, \& Aiello-Vaisberg (2022). Estudo psicanalítico do filme "Divórcio: até que o amor exploda". https://doi.org/10.32467/issn.2175-3628v23n1a12 
situação acaba por se modificar quando, unidos em criatividade, o marido passa a fabricar um molho de tomate que segue a receita da esposa, tornando-se um empresário de sucesso. Ultrapassadas as dificuldades financeiras, mudam-se, com as duas filhas, para uma casa luxuosa e passam a desfrutar a riqueza de modo francamente consumista, sendo aí surpreendidos por um processo de desgaste, em função do qual a convivência se revela crescentemente insuportável. Começa uma guerra entre ambos, incentivada por advogados interessados em lucrar com o litígio, que é pontuada por peripécias que provocam o riso da plateia.

As filhas pouco aparecem e não são realmente vistas, em suas necessidades de desenvolvimento, por pais muito absorvidos pela batalha conjugal. Aparentemente, a própria guerra acaba por se revelar o avesso da paixão que, assim como escapara, volta com pleno vigor. Assim, o enredo finaliza com o retorno do casal à posição inicial de paixão recíproca.

A interpretação do material fílmico que realizamos dispensa maiores detalhamentos, uma vez que consiste no uso do método que, como bem demonstrou Herrmann (2004), é o elemento invariante que se tem mantido, de fato, ao longo das décadas. Ou seja, se as teorias e os métodos de tratamento psicanalítico se diversificaram, na passagem do tempo, de acordo com o aparecimento de novas demandas, a verdade é que o método investigativo, propriamente dito, tem-se revelado sempre fecundo e suficiente para a realização de novas descobertas. Entretanto lembramos, apenas por excesso de zelo, que temos por hábito utilizar as palavras de ordem, forjadas por Herrmann (1979/1991), que consistem num apoio interessante no que tange a colocar a atenção flutuante e a associação livre de ideias, pilares do método psicanalítico, em uso. São elas: "Deixar que surja", "Tomar em consideração" e "Considerar a configuração de sentido emergente".

Esse sentido emergente terá sempre, de acordo com Politzer (1928/1998), um caráter afetivo-emocional intrínseco à vida como acontecer sócio-humano. Essa assertiva está baseada na distinção, destacada pelo filósofo, entre vida enquanto fenômeno biológico e vida enquanto drama, vocábulo que usa na acepção grega etimológica, para referir o conceito de ação humana, que seria posteriormente transferida para o gênero teatral.

Insiste Politizer (1928/1998), desde as primeiras páginas de seu livro, que toda experiência vivida é drama, porque vinculada às ações, próprias e alheias, o que depende do fato de se estar biologicamente vivo, mas a isso não se reduz. Nessa linha, celebra a descoberta freudiana de que o sonho só pode ser psicologicamente compreendido levando-se em conta a vida dramática do sonhador, e que esse tipo de conhecimento, que pode fundar uma atuação clínica, não pode ser confundido com estudos neurofisiológicos sobre o sonhar. Percebe-se, aí, com clareza, que a experiência vivida do sonhador, vale dizer, sua experiência concreta de vida, sua experiência dramática, corresponde ao objeto de estudo de uma psicologia concreta, para a qual o texto freudiano apontava quando não sucumbia a exigências cientificistas da época, que levaram a especulações metapsicológicas sobre um aparelho psíquico.

Bleger (1963/2007) entusiasmou-se, como tantos, com o texto politzeriano por um motivo bastante preciso: pelo fato de entender que a atuação do psicanalista se dava, inevitavelmente, no campo relacional, focalizando motivos e razões afetivo-emocionais, segundo as quais se desdobrava a experiência vivida do paciente. Essa atuação não se beneficiava minimamente das construções metapsicológicas que conformavam um aparelho psíquico percorrido por energias impessoais e preenchido por representações. 
Ou seja, foi a partir da detecção de uma incompatibilidade epistemológica entre uma teoria que focalizava organismos biologicamente vivos para explicar uma clínica em que se atendiam pessoas dramaticamente vivas.

Assim, Bleger (1963/2007), que nunca deixou de usar a psicanálise enquanto método investigativo e método de tratamento, cedo notou a necessidade de abandonar toda teorização metapsicológica e de redefinir certos conceitos, para obter coerência entre prática clínica e referencial teórico. Entendeu que considerar que o inconsciente, que é um constructo teórico, que serve para explicar inconsistências dramáticas de atos humanos, como objeto de uma ciência, não passava de equívoco perigoso, por afastar-se da vida concreta. Rejeitando, assim, a ideia metapsicológica de uma mente inconsciente, de inconsciente substantivado, o argentino concluiu ser necessário definir o objeto de uma psicologia concreta, que se valeria do método freudiano, para produzir conhecimento sobre fenômenos humanos e não sobre uma abstração especulativamente criada. Assim, propôs, como objetivo das ciências humanas, entre as quais estaria a psicologia, os atos de seres humanos concretos, e retraduziu o conceito de inconsciente como campo de sentido afetivo-emocional.

Nos textos blegerianos, as ações dos seres humanos concretos figuram por meio do conceito de conduta, a qual não se confunde com a acepção que encontramos nos textos comportamentalistas, sendo definida como conjunto de atos humanos que são inerentemente carregados de sentidos como acontecer humano (Bleger, 1963/2007). Nessa perspectiva, todas as ciências humanas compartilham a conduta dos seres humanos como objeto de estudo, sendo que cada uma delas se encarrega de um diferente tipo de sentido. A psicologia focaliza o sentido afetivo-emocional, o que significa que lida com a experiência vivida por pessoalidades individuais e coletivas, que sempre é só parcialmente consciente. As demais ciências trabalham com a conduta buscando acessar sentidos econômicos, culturais, políticos etc.

Do ponto de vista da psicologia psicanalítica concreta, os atos humanos, sejam expressos simbolicamente, corporalmente, como atuação no mundo externo ou como produtos remanescentes dessa atuação, são considerados como emergentes de campos de sentido afetivo-emocional ou inconscientes intersubjetivos, que estariam na base da produção dos fenômenos intra-subjetivos e transubjetivos (Berenstein \& Puget, 1997). Sendo assim, o conceito de campos de sentido afetivo-emocional deve ser definido como uma espécie de fundo, ontologicamente idêntico às próprias condutas. Os campos de sentido afetivo emocional, que devem ser sempre considerados como relativos às condutas cuja compreensão psicanalítica se visa, seriam zonas psicológicas a partir das quais emergem novas condutas, mais ou menos conservadoras ou transformadoras, que configuram novos campos, mais ou menos conservadores ou transformadores, e assim por diante, num movimento que pode ser visualizado como uma espiral tridimensional. Esses campos se organizam ao redor de crenças, valores e sentimentos, usualmente não conscientes, algo que se sente e em que se crê de modo pré-reflexivo.

Portanto, por meio do uso do método psicanalítico, e auxiliadas pelas palavras de ordem de Herrmann (1979/1991), chegamos a definir crenças, valores ou sentimentos, que não vemos como meramente internos, mas como elementos ao redor dos quais os campos de sentido afetivo-emocional se organizam como regiões intersubjetivas. No caso o filme, que aqui utilizamos para levar a cabo uma reflexão sobre a idealização da relação conjugal, no contexto da família nuclear com filhos, chegamos à proposição interpretativa de três campos de sentido afetivo-emocional, que 
apresentaremos a seguir, com vistas a desenvolver interlocuções reflexivas, cumprindo o objetivo estabelecido no presente estudo.

\section{INTERPRETAÇÕES E INTERLOCUÇÕES}

A consideração psicanalítica do filme permitiu a criação/encontro de três campos de sentido afetivo-emocional: "Até que a morte nos separe", "Era vidro e se quebrou" e "Usando os filhos". Tais campos correspondem a inconscientes intersubjetivos a partir dos quais emergem os atos e manifestações dos personagens do filme. A seguir, compartilharemos nossas interpretações por meio da definição desses campos, que buscaremos ilustrar recordando trechos do filme.

O primeiro campo de sentido afetivo-emocional, "Até que a morte nos separe", organiza-se ao redor da crença/fantasia de que homens e mulheres só se sentem felizes e completos quando seu casamento se baseia em amor eterno. Podemos evocar, como exemplo de conduta que emerge a partir desse campo, a cena em que a personagem principal estava no altar, ao lado do abastado noivo aprovado pelos pais, mas foi surpreendida por um antigo namorado, que interrompeu a suntuosa cerimônia e a pediu em casamento diante de todos. Ela não pensou duas vezes e foi embora com o amado para iniciar uma vida com poucos recursos financeiros. A partir daí, eles iniciaram uma vida simples e, juntos, acabam construindo uma família com duas filhas e um grande negócio, uma fábrica de molho de tomate, que representava a verdadeira união do casal.

O segundo campo de sentido afetivo-emocional, "Era vidro e se quebrou", organiza-se ao redor da crença/fantasia de que o fim do casamento seria decorrente de uma experiência de decepção com o outro. Esse campo pode ser ilustrado por uma fala da esposa de que se irritava com tudo o que o marido fazia - sua risada, seu interesse por carros etc. - enquanto ele criticava duramente o casamento em suas reuniões de trabalho. Havia descontentamento mútuo em relação ao consumismo do outro.

Também podemos nos lembrar de uma cena que evidencia o afastamento dos cônjuges, em que toda família está assistindo TV, mas o casal não está mais abraçado como no passado. Desta vez, não parece haver contato algum, mostram-se entediados e distanciados. O sofrimento é decorrente da dúvida sobre quem seria o responsável pelo problema - o outro, que se tornou desagradável ou a própria pessoa, que teria escolhido mal o(a) parceiro(a)? Temos aqui uma configuração que se assemelha a uma dúvida de consumidor, a saber, quem errou, a empresa que vendeu um produto de má qualidade, ou o consumidor, que escolheu mal? Esse drama ilustra como as pessoas são invadidas pelo que prevalece na estrutura da sociedade consumista.

Quando a separação se concretiza, ocorrem cenas como provocações por mensagens de celular, destruição de objetos afetivamente importantes do outro cônjuge - tais como a coleção de sapatos da esposa e carro importado do marido, além da disputa acirrada pela atenção e guarda das filhas. Vale destacar que o encaminhamento judicial do problema acaba por potencializar os atritos, uma vez que os profissionais parecem ter mais interesse em incentivar os conflitos do que na busca de sua solução.

Por fim, o terceiro e último campo, "Usando os filhos", organiza-se ao redor da crença/fantasia de que os filhos são usados durante a separação conjugal. No filme "Divórcio: Até que o amor exploda" (Amorim, 2017), a disputa de guarda não parece ocorrer a partir de preocupações realistas com as necessidades das filhas, mas tãosomente como modo de atacar o outro, num contexto geral de empobrecimento afetivo

Fonseca-Inacarato, Gallo-Belluzzo, \& Aiello-Vaisberg (2022). Estudo psicanalítico do filme "Divórcio: até que o amor exploda". https://doi.org/10.32467/issn.2175-3628v23n1a12 
da relação entre pais e filhas. As filhas são usadas para participarem dos conflitos do casal, segundo os interesses de cada um. Numa cena do filme, que retrata o dia das meninas saírem com o pai, este compra muitos presentes para elas, que demonstram insatisfação e até irritação, pois fica evidente que ele não está conectado com seus interesses ou necessidades, uma vez que sua conduta é motivada pelo desejo de provar que é mais poderoso que a mãe delas.

Cumprida a apresentações dos três campos de sentido afetivo-emocional, vemonos em condição de encaminhar algumas interlocuções reflexivas, lembrando que esse tipo de estudo é inerentemente inconclusivo, colocando-se como contribuição para o debate atual, sobre uma questão altamente significativa do ponto de vista concreto.

O primeiro campo, "Até que a morte nos separe", é aquele que mais claramente aponta para a questão que motivou o presente estudo, vale dizer a idealização do vínculo conjugal. A menção a uma situação duradoura, porque no imaginário a morte sobreviria na velhice, segundo a fantasia "quero envelhecer ao seu lado", que provavelmente expressa o desejo que, nos contos de fada, é resumido pela fórmula "e viveram felizes para sempre".

A nosso ver, esse primeiro campo aponta para um modelo idealizado de relação, que teria surgido na modernidade, como padrão burguês (Biroli, 2014; Lejarraga, 2003). Se em outras configurações históricas e culturais, a relação amorosa não era vista como necessária para a constituição do vínculo conjugal, a partir de certo momento da história ocidental, uma forma idealizada de amor, muitas vezes referida como amor romântico, passou a ser considerada como ingrediente indispensável ao casamento, imaginado como o lugar de felicidade, onde paixão e erotismo se integrariam como elementos de exaltação da vida amorosa. Este novo modelo de casamento cria a expectativa de que, uma vez casados, os cônjuges sejam felizes e se mantenham duradouramente apaixonados, vivenciando um desejo erótico inesgotável pelo parceiro, a partir do qual a adoção da fidelidade monogâmica seria uma consequência natural.

De acordo com a psicanálise clássica, o amor idealizado ocorreria numa busca pessoal por completude, fantasiada por meio do encontro com um outro também idealizado. O ser amado seria visto como alguém que possui qualidades e valores perfeitos que complementam aquilo que falta. A idealização do ser amado, assim como a aspiração de união com ele, visaria uma fusão narcísica, uma sensação de plenitude.

De acordo com Freud (1914/1996), todo amor corresponderia a um reencontro, ou seja, a uma volta ao passado em busca do objeto parental perdido. Desta forma, sob o encantamento da paixão, ocorreria a ilusão de que o outro seria aquilo que se espera dele, seria o amor verdadeiro, a única pessoa capaz de inspirar tal sentimento. Ora, claro está que a manutenção dessa configuração vincular é um desafio praticamente impossível de manter porque, em última instância, repousa numa visão divalente segundo a qual tanto o self como o outro visto como seres completamente bons, estão sempre vinculados, na fantasia, a seres perfeitamente maus (Bleger, 1963/2007). Não há lugar no mundo do amor dito romântico para o que, na linguagem winnicottiana, pode ser designado como pessoa total, ou seja, para o ser humano que, justamente por não ser um feixe de projeções, e sim uma unidade existencial autônoma, tanto me frustra como me realiza, no plano da convivência cotidiana (Winnicott, 1971/1975).

Contudo, cumpre fazer um reparo importante, pois durante muito tempo o casamento perdurou e perdura como a área por excelência da realização feminina, principalmente quando conduz à maternidade, que ainda é contemporaneamente imaginada como indispensável à realização da mulher (Schulte et al., 2019; Visintin \& 
Aiello-Vaisberg, 2017). Assim, o homem pode conceber o casamento como importante, mas nele não se decide, de modo definitivo, o seu valor pessoal, para o qual pesam muito a conquista de uma situação de estabilidade financeira e sucesso profissional. Tampouco o sexo conjugal é concebido, pelo homem, como possibilidade de alcançar uma realização erótica incomparável, não sendo infrequente a ideia de que os homens casados deixam de usufruir as delícias da sedução e da conquista de mulheres, sempre no plural, apenas em nome da garantia de sexo conjugal frequente capaz de proporcionar prazer e relaxamento (Rocha \& Feisterseifer, 2019).

A conjunção das diferentes expectativas, feminina e masculina, e o fato de a vida cotidiana colocar à prova tudo o que é idealisticamente imaginado, resulta em conflitos e dificuldades de convivência que, na comédia "Divórcio: Até que o amor exploda" (Amorim, 2017) expressam-se por um deslocamento, um trânsito, que se faz por meio do abandono do campo "Até que a morte nos separe" e da chegada ao campo "Era vidro e se quebrou".

Entretanto, cabe perguntar sobre as condutas que surgem quando o campo "Até que a morte nos separe", que pode ter-se sustentado durante algum tempo sobretudo pela fantasia feminina de que algo de grande e precioso valor foi conquistado, é substituído pela percepção de que o amor idealizado é uma ilusão. O filme é bem claro nesse sentido, brindando quem o assiste com uma série de brigas e disputas que vão num crescendo de desconsideração e desrespeito recíprocos. Sabemos, por experiência clínica e de vida, que nem sempre esse segundo campo desemboca na busca pela separação, pois muitos casais vivem essa situação ao longo de décadas, coabitando sob um mesmo teto. Contudo, no nosso material, uma das condutas emergentes do "Era vidro e se quebrou" é justamente a demanda de divórcio.

Aqui o filme traz, com muita clareza, um fenômeno frequente: a entrada de terceiros, ligados ao âmbito jurídico. Esse evento não raras vezes incentiva as brigas e disputas, motivo pelo qual tem sido nomeado como cultura do litígio, algo que parece estar de fato bastante difundido em nossa sociedade, especialmente dentro do judiciário, conforme foi possível notar no material analisado: os personagens advogados levantavam a bandeira do litígio, chegando a desconsiderar os desejos de seus clientes. Essa forma de conduzir as disputas jurídicas vem sendo muito questionada por trazer, com frequência, consequências bastante danosas. Nos últimos anos, estão se intensificando movimentos e ações no sentido de propagar o que vem sendo chamado de cultura da pacificação, na busca de prevenir tanto o agravamento dos conflitos em andamento, como a instauração de novos processos litigiosos (Suter \& Cachapuz, 2017).

Como vemos, há uma clara a solidariedade existente entre os dois primeiros campos de sentido afetivo-emocional, "Até que a morte nos separe" e "Era vidro e se quebrou", porque um é, evidentemente, o contrário do outro. Percebemos, portanto, que a idealização do amor conjugal perpassa os dois primeiros campos de sentido afetivoemocional aqui retomados: no primeiro, "Até que a morte nos separe", o amor é vivido de forma plena durante um certo tempo; no segundo, "Era vidro e se quebrou", predominam a decepção e as agressões mútuas, já que as expectativas não se cumprem, e aquele(a) vivido como ser parcial completamente bom se transforma em ser parcial completamente mau - pois nesse tipo de mundo vincular não há espaço para pessoas totais. Isso significa que aí não há condições para vivenciar o amor de modo criativo e amadurecido, vale dizer, com respeito à alteridade a partir da qual não faz sentido usar o outro como objeto. 
Se o interjogo entre os campos "Até que a morte nos separe" e "Era vidro e se quebrou" mostra que uma felicidade aparente e transitória, baseada na visão do outro como ser completamente bom, acaba, antes cedo do que tarde, dando lugar ao conflito e à discórdia crescente, num movimento que faz do aliado de ontem o inimigo de hoje, um terceiro campo de sentido afetivo-emocional, "Usando os filhos", vem lembrar a existência das filhas. De fato, esse campo se coloca, a partir da consideração psicanalítica do enredo, como menos importante, já que a cena é tomada pela realização apaixonada dos primeiros tempos do casamento e pelo ódio mútuo que se revela na crise conjugal. As filhas praticamente ocupam o lugar de figurantes, tanto nas cenas de amor como naquelas de decepção e ódio que os pais sentem um pelo outro.

Quando refletimos sobre o sentido do campo "Usando os filhos", concluímos que as crianças ficaram ofuscadas pelo fato da relação conjugal ser estruturada de modo divalente (Bleger, 1963/2007). De fato, todo o filme pode ser descrito como evidência de que o amor idealizado não se harmoniza com a assunção de encargos parentais, já que os amantes se bastariam e se manteriam à disposição um do outro. Por outro lado, quando o amor apaixonado se transforma em seu avesso, as batalhas conjugais também consomem toda a energia e atenção dos combatentes, que se veem sem possibilidade de exercer qualquer tipo de dedicação verdadeira às crianças, tendo em vista ajudá-las a assumir suas existências individuais de modo cada vez mais autônomo.

Fizemos um exercício de tentar compreender o lugar ocupado pelos filhos na vida dos pais, personagens centrais da trama, nas duas diferentes fases do relacionamento conjugal e dos respectivos campos de sentido afetivo-emocional. Percebemos que, quando imperava o amor idealizado em sua fase inicial e bemsucedida, as crianças ocuparam o lugar de "filhos decorativos", na medida em que compunham o quadro de sucesso da família ideal. No campo "Era vidro e se quebrou", observamos os "filhos como dever", que precisavam ser administrados, fazendo parte dos "bens" que mereceriam cuidado, sem que houvesse maiores demonstrações de carinho ou atenção às suas necessidades afetivas. Quando ocorreu a separação os filhos apareceram como "moeda de troca" nas disputas, o que está relatado na literatura (Gorin et al., 2017). Enfim, quando vigoram os dois campos, "Até que a morte nos separe" e "Era vidro e se quebrou", os filhos dificilmente são atendidos em suas necessidades, caracterizando uma situação de falha ambiental, que não favorece seu desenvolvimento afetivo-emocional (Winnicott, 1960/1990).

Quando lembramos que a família nuclear, imaginada como realização do amor idealizado, é vista como o melhor lugar de cuidado e proteção das novas gerações, logo concluímos estar diante de uma solução cultural bastante contraditória. A idealização do vínculo conjugal revela-se como fenômeno que contribui fortemente para a busca do casamento com vistas à assunção constituição da família, mas não contribui para favorecer sua sustentabilidade ao longo dos anos, conflitando, portanto, com a responsabilidade e o trabalho, que aqui usamos no sentido forte do termo, de cuidado dos filhos. 


\section{CONSIDERAÇÕES FINAIS}

Apesar dos limites inerentes aos estudos teórico-reflexivos, dos quais o presente evidentemente não escapa, consideramos ser importante reiterar que a idealização do vínculo conjugal se constitui como base frágil para a constituição da família nuclear, enquanto locus privilegiado do cuidado dos filhos, como foi indicada na produção cultural aqui abordada. Assim, acreditamos que tal idealização deva ser combatida, pois aquilo que, à primeira vista, pode ser tomado como inofensivo, na verdade carrega consigo um potencial bastante significativo de produção de sofrimento emocional que, nesse caso, é socialmente determinado (Schulte et al., 2019), atingindo indivíduos e grupos no presente e no futuro. Entendemos, assim, que a própria manutenção da família nuclear depende da desmistificação do chamado amor romântico que, psicologicamente, pode ser pensado como um sintoma de imaturidade emocional.

Por outro lado, mesmo quando a idealização não domina a cena conjugal, é evidente que o casal fica sobrecarregado quando nascem os filhos, mesmo sendo mais comum que esse excesso de responsabilidade e de trabalho tenda a ser assumido pela mulher, tida, ideologicamente, como mais preparada, biológica e culturalmente, para exercer atividades de cuidado de crianças e adolescentes. Esse problema pode ser em parte amenizado se outras pessoas, além dos próprios genitores, tais com a família extensa, a comunidade e a escola, incluindo pessoas de sexo masculino, puderem se envolver com as tarefas. Ou seja, reconhecendo as dificuldades atualmente enfrentadas, vale a pena conjecturar sobre a necessidade de criação de novas formas de proteção às novas gerações, sem dúvida o passo fundamental para a sustentabilidade de nossa existência enquanto humanidade.

\section{REFERÊNCIAS}

Abade, F., \& Romanelli, G. (2018). Paternidade e paternagem em famílias patrifocais. Revista Estudos Feministas, 26(2), e50106. http://dx.doi.org/10.1590/1806-9584-2018v26n250106

Aiello-Vaisberg, T. M. J., Gallo-Belluzzo, S. R., \& Visintin, C. D. (2020). Maternidade e sofrimento social em tempos de Covid 19: Estudo de Mommy Blogs. Scielo Preprints, 1-17. https://doi.org/10.1590/SciELOPreprints.356

Alves-Silva, J. D., Scorsolini-Comin, F., \& Santos, M. A. (2017). Bodas para uma vida: Motivos para manter um casamento de longa duração. Temas em Psicologia, 25(2), 487-501. https://dx.doi.org/10.9788/TP2017.2-05

Amorim, P. (2017). Divórcio: Até que o amor exploda [filme]. Brasil: Filmland Internacional. Distribuidora Warner Bros. Pictures.

Arrais, R. H., Gomes, I. C., \& Campos, E. M. P. (2019). A monoparentalidade por opção e seus aspectos psicossociais: Estudo de revisão integrativa. Revista da SPAGESP, 20(1), 39-53. Disponível em: https://dialnet.unirioja.es/servlet/articulo?codigo $=7155478$

Batoni, B. R. (2020). Trabalho profissional e trabalho reprodutivo no imaginário coletivo de universitárias. Dissertação de Mestrado em Psicologia], Pontifícia Universidade Católica de Campinas, Campinas/SP.

Berenstein I., \& Puget J. (1997). Lo vincular: Clínica y técnica psicoanalítica. Paidós. 
Bernardi, D., Mello, R., \& Féres-Carneiro, T. (2019). Ambivalências frente ao projeto parental: Vicissitudes da conjugalidade contemporânea. Revista da SPAGESP, 20(1), 9-23. Disponível em: https://dialnet.unirioja.es/servlet/articulo?codigo=7155480

Biroli, F (2014). Família: Novos conceitos. Fundação Perseu Abramo.

Bleger, J. (2007). Psicología de la conducta. Paidós. (Original publicado em 1963)

Bueskens, P. (2019). Deregulated patriarchy and the new sexual contract: One step forwards and two steps back. Journal of the Motherhood Initiative, $10(1 \& 2), 59-$ 81. Disponível em: https://www.semanticscholar.org/paper/DeregulatedPatriarchy-and-the-New-Sexual-Contract $\% 3 \mathrm{~A}-$

Bueskens/1ab3d71b24969a8c2005446b20dd93fe503a51c4

Colégio Notarial do Brasil. (2021). Conjur: Número de divórcios explode na pandemia $e$ gera oportunidades de negócio. Disponível em: https://www.cnbsp.org.br/?url_amigavel=1\&url_source=noticias\&id_noticia=20820 $\& 1 j=1366$

Federici, S. (2019). O ponto zero da revolução: Trabalho doméstico, reprodução e luta feminista. São Paulo: Elefante.

Freud, S. (1996). Sobre o narcisismo: Uma introdução. In S. Freud, Obras Psicológicas Completas, vol. XIV (pp. 85-119). Imago. (Original publicado em 1914)

Freud, S. (1976). Dois verbetes de enciclopédia: 'Psicanálise" e "Teoria da libido". In S. Freud, Obras Psicológicas Completas, vol. XVIII (pp. 285-314). Imago. (Original publicado em 1922)

Freud, S. (1976). Delírios e sonhos na Gradiva de Jensen. In S. Freud, Obras Psicológicas Completas, vol. IX (pp. 13-98). Imago. (Original publicado em 1907)

Freud, S. (1974). O Moisés de Michelangelo. In S. Freud, Obras Psicológicas Completas, vol. XIII (pp. 249-280). Imago. (Original publicado em 1914)

Freud, S. (1970). Leonardo da Vinci e uma lembrança da sua infância. In S. Freud, Obras Psicológicas Completas, vol. XI (pp. 53-124). Imago. (Original publicado em 1910)

Gorin, M. C., Féres-Carneiro, T., \& Machado, R. N. (2017). Aniversário dos filhos: Juntos ou separados? Repercussões do divórcio na perspectiva dos pais. Estudos e Pesquisas em Psicologia,17(3), 1084-1100. Disponível em: http://pepsic.bvsalud.org/scielo.php?script=sci_arttext\&pid=S180842812017000300016\&lng=pt\&tlng=pt.

Gottlieb, A. \& DeLoache, J. (2016). A world of babies: Imagined childcare guides for eight societies. Cambridge: Cambridge University Press.

Greenberg, J.R., \& Mitchell, S.A. (1994). Relações objetais na teoria psicanalítica. Artes Médicas.

Herrmann, F. (2004). Pesquisando com o método psicanalítico. In F. Herrmann e T. Lowenkron (orgs). Pesquisando com o método psicanalítico (pp. 43-83). São Paulo: Casa do Psicólogo.

Herrmann, F. (1991). O método psicanalítico. Brasiliense. (Original publicado em 1979) Lejarraga, A. L. (2003). Freud e Winnicott: Do apaixonamento à capacidade de amar. Pulsional: Revista de Psicanálise, 16(165), 42-49. Disponível em: http://portal.revistas.bvs.br/index.php?mfn=3095\&about=access\&lang=pt\#

Leonardo, F. A. M., \& Morais, A. G. L. (2017). Família monoparental feminina: A mulher como chefe de família. Revista do Instituto de Políticas Públicas de Marília, 3(1), 11-12. http://doi.org/10.33027/2447-780X.2017.v3.n1.02.p11 
Mitchell, S. (1988). Relational concepts in psychoanalysis. Harvard University Press.

Politzer, G. (1998). Crítica dos fundamentos da Psicologia: A psicologia e a psicanálise. Piracicaba: Unimep. (Original publicado em 1928)

Rocha, F. A. \& Fensterseifer, L. (2019). A função do relacionamento sexual para casais em diferentes etapas do ciclo de vida familiar. Contextos Clínicos, 12(2), 560-583. http://dx.doi.org/10.4013/ctc.2019.122.08

Rosa, D. C. J., Lima, D. M., Peres, R. S., \& Santos, M. A. (2019). O conceito de imaginário coletivo em sua acepção psicanalítica: Uma revisão integrativa. Psicologia Clínica, 31(3), 577-595. https://doi.org/10.33208/PC19805438v0031n03A09

Schulte, A. A., Gallo-Belluzzo, S. R., \& Aiello-Vaisberg, T. M. J. (2019). A experiência emocional de autoras de Mommy Blogs. Estudos Interdisciplinares em Psicologia, 10(1), 107-130. https://doi.org/10.5433/2236-6407.2019v10n1p107

Souza, F. H. O. (2018). Mutações sociais, família e parentalidade: Uma entrevista com Gerárd Neyrand. Psicologia \& Sociedade, 30, e161410, 1-7. http://dx.doi.org/10.1590/1807-0310/2018v30161410

Stolorow, R. D., \& Atwood, G. E. (1992). Contexts of being: The intersubjective foundations of psychological life. Analytic Press.

Suter, J. R., \& Cachapuz, R. R. (2017). A mediação como instrumento fortalecedor do acesso à justiça e da democracia na resolução de conflitos familiares. Scientia Iuris, Londrina, 21(2), 237-261. https://doi.org/10.5433/2178-8189.2017v21n2p237

Visintin, C. D. N., \& Aiello-Vaisberg, T. M. J. (2017). Maternidade e sofrimento social em mommy blogs brasileiros. Revista Psicologia: Teoria e Prática, 19(2). http://dx.doi.org/10.5935/1980-6906/psicologia.v19n2p98-107

Winnicott, D. W. (1975). A criatividade e suas origens. In D. W. Winnicott, O brincar e a realidade. (pp. 95-120). Imago (Original publicado em 1971)

Winnicott, D. W. (1990). Teoria do relacionamento paterno-infantil. In D. W. Winnicott, $O$ ambiente e os processos de maturação: Estudos sobre a teoria do desenvolvimento emocional (pp. 38-54). Artes Médicas. (Original publicado em 1960)

Submetido: $23 / 03 / 2021$

Reformulado: $23 / 04 / 2021$

Aceito: $30 / 04 / 2021$

\section{Sobre as autoras:}

Gisele Meirelles Fonseca-Inacarato é doutora em Psicologia pela Pontifícia Universidade Católica de Campinas e docente da Universidade Presbiteriana Mackenzie. Sueli Regina Gallo-Belluzzo é doutora em Psicologia pela Pontifícia Universidade Católica de Campinas.

Tânia Maria José Aiello-Vaisberg é Livre docente em Psicopatologia pela Universidade de São Paulo e professora do Programa de Pós-graduação em Psicologia da Pontifícia Universidade Católica de Campinas.

Correspondência: giseleinacarato@gmail.com 